\title{
COLORECTAL CANCER SCREENING
}

\section{Guidelines for monitoring of patients with ureterosigmoidostomy}

\section{R J Woodhouse}

$\mathrm{N}$ eoplasms can occur at the anastomosis of ureter and bowel probably only in the presence of faeces. In practice the only patients at risk are those with ureterosigmoidostomies or one of the variations, such as the Mainz II or Mansoura operations.

The neoplasms are adenomas or adenocarcinomas. It is thought that adenomas develop first and subsequently undergo malignant degeneration. The observation that the mean latent period for the development of adenomas is 19.8 years and for carcinomas is 25.8 years suggests that this process takes a mean of six years. ${ }^{1}$ It is uncertain whether the neoplasms arise from the intestinal or the ureteric epithelium or from the anastomosis itself. Although neoplasms other than adenomas and adenocarcinomas have been reported in patients with ureterosigmoidostomy, they are rare and probably a chance finding.

Experimental evidence is difficult to interpret as some laboratory animals develop neoplasms very readily in urinary reservoirs and yet other animals develop few, thus the results cannot be translated from one species to another with confidence. However, it seems that when ureteric epithelium and colonic mucosa are anastomosed and exposed to faeces and urine, adenomas and adenocarcinomas are common. These neoplasms are rare when ileum is interposed between ureters and colon. When urine or faeces are excluded, a few neoplasms occur and seldom are malignant.

\section{EXECUTIVE SUMMARY}

Neoplasia at the anastomosis of the ureters and colon in patients with any urinary diversion that mixes urine and stool (in effect, ureterosigmoidostomy and its variations) occurs in about $24 \%$ of patients at 20 years of follow up. The earliest recorded is 10 years after formation.

All patients should have a flexible sigmoidoscopy once per year, commencing 10 years after surgery. (Recommendation Grade: B)

In patients who have had a ureterosigmoidostomy but have subsequently been converted to an alternative diversion, flexible sigmoidoscopies should still be done unless it is known that the ureteric anastomoses were removed. (Recommendation Grade: B)

\section{PREVALANCE AND INCIDENCE \\ Timing}

The first neoplasm was reported in $1929 .{ }^{2}$ However, as the mortality in patients with ureterosigmoidostomy was so high, it was not recognised as an important complication until almost 60 years later. ${ }^{3}$

It seems that the neoplastic process is initiated in a short time and is not reversed if the urinary diversion is changed but the anastomosis left intact. In one patient, the ureterosigmoidostomy was in place for only nine months before a change was made to an ileal conduit; the anastomosis was left and developed an adenocarcinoma 14 years later. The shortest time from formation of the ureterosigmoidostomy to the development of a neoplasm is 10 years. ${ }^{4}$
The total number of patients with a ureterosigmoidostomy in the United Kingdom is unknown. Based on figures from Germany, there is likely to be only one or two patients per 100000 population. ${ }^{5}$ Some would not have reached the 10th year. It is probable that a UK population of 300000 would produce only three patients requiring flexible sigmoidoscopy for this indication.

\section{Risk}

Estimates of the risk of developing colonic cancer are plagued by lack of a uniform population. Estimates vary between 100 and 7000 times that in the normal population. In a definitive review of the literature in 1982 Stewart et al accepted the lower figure. ${ }^{1}$

Patients with exstrophy and a ureterosigmoidostomy form an interesting group whose natural risk of colonic carcinoma seems to be normal. Strachan divided 103 patients followed up for more than 20 years into two groups: an at risk group of 42 patients who had had urinary and faecal streams mixed at some time and 61 low risk patients who had had an early diversion into a conduit or had a successful exstrophy reconstruction. There were no colonic neoplasms in the low risk patients and 10 in the at risk group (24\%). This gives relative risk of 1726 times that of the normal population. ${ }^{6}$

\section{Neoplasia in other urinary reservoirs}

Stomach, ileum, caecum, colon, and rectum are all widely used as urinary reservoirs in isolation from the gastrointestinal tract. There is some experimental evidence to suggest ileal and colonic reservoirs may be at risk of the development of neoplasia. In particular, increased levels of nitrosamines have been found in the urine of such reservoirs in the presence of infection. ${ }^{78}$ To date only a few neoplasms have been reported. There were no neoplasms in a series of isolated rectal reservoirs followed up for up to 30 years. ${ }^{9}$ In a review article on neoplasia in urinary diversions 14 neoplasms were identified from the literature.$^{10}$ However, there were one or more unusual features in 11. Six developed tumours in areas remote from the urinary anastomosis; 10 occurred in patients with vesical tuberculosis; one occurred so quickly after formation of the reservoir that a recurrence of a known pre-existing lesion was most probable.

\section{RECOMMENDATIONS}

Patients who have a ureterosigmoidostomy or any of the modern variations such as the Mainz II or Mansoura operations should have a flexible sigmoidostomy to visualise the colon up to and just beyond the higher ureteric anastomosis. The examinations should begin on the 10th anniversary of the original operation and should be repeated annually. (Grade B recommendations)

The anastomosis normally looks like a small cherry, 4 or 5 $\mathrm{cm}$ in diameter. Routine biopsies are not required. All other lesions should be biopsied. Polypoid lesions should not be removed with an endoscopic snare as the anastomosis may be 
damaged leading to urinary leakage. Lesions found to be adenomas or adenocarcinomas should be locally resected. Patients may, after proper advice, opt for a different diversion or for another ureterosigmoidostomy.

Patients who have had a ureterosigmoidostomy but with subsequent conversion to a different diversion, should also have annual flexible sigmoidoscopies unless the ureteric anastomosis is known to have been removed.

At present, there is insufficient evidence to recommend routine endoscopic monitoring of other types of intestinal urinary reservoir in which stool and urine have never mixed.

\section{COST AND BENEFITS}

The number of patients with a ureterosigmoidostomy is very small. All are likely to be under regular urological follow up for other reasons. With an incidence of neoplasia of $24 \%$ in 20 years a population of 100 affected patients would produce 1.2 cases per year. However, the number of patients with ureterosigmoidostomy in the community is unknown. In Germany, it has been calculated that the incidence is 247 cases in a ureterosigmoidostomy population of $100000 .^{5}$ The number for a UK population of 300000 would be 2 or 3, although the number is rising.

\section{AUDIT}

Patients with ureterosigmoidostomy should be identified by their urologist and follow up maintained within a urology department.

\section{Author's affiliations}

C R J Woodhouse, Institute of Urology and Nephrology, Gower Street Campus, 48 Riding House Street, London W1P 7PN, UK;

CWoodhouse2@compuserve.com

Accepted for publication 10 June 2002

\section{REFERENCES}

1 Stewart $M$, Macrae FA, Williams CB. Neoplasia and ureterosigmoidostomy: a colonoscopic review. Br J Surg 1982;69:414-16. (Category:Ilb)

2 Hammer E. Cancer du colon sigmoide dix ans apres implantation des ureteres d'une vessie exstrophiee. J Urol (Paris) 1929;28:260-3. (Category:IV)

3 Stewart M. Urinary diversion and bowel cancer. Ann R Coll Surg 1986;68:98-102. (Category:IV)

4 Spence HM, Hoffman WW, Fosmire GP. Tumour of the colon as a late complication of ureterosigmoidostomy for exstrophy of the bladder. $\mathrm{Br} J$ Urol 1979:51:466-70. (Category: IV)

5 Kalble T, Tricker AR, Friedl P, et al, Mohring K. Ureterosigmoidostomy: long term results, risk of carcinoma and etiological factors for carcinogenesis. J Urol 1990;144:1110-14. (Category:IV)

6 Strachan JR, Woodhouse CRJ. Malignancy following ureterosigmoidostomy in patients with exstrophy. $\mathrm{Br} J$ Surg 1991;78:1216-18. (Category:III)

7 Nurse DE, Mundy AR. Assessment of the malignant potential of cystoplasty. Br J Urol 1989;64:489-92. (Category:Ilb)

8 Groschel J, Riedasch G, Kalble T, et al. Nitrosamine excretion in patients with continent ileal reservoirs for urinary diversion. J Urol 1992;147:1013-16. (Category:Ilb)

9 Kroovand RL, Boyce HH. Isolated vesicorectal internal diversion: a 37 year review of the Boyce-Vest procedure. J Urol 1988;140:572-3 (Category:IV)

10 Filmer RB, Bruce JR. Malignancies in bladder augmentations and intestinal conduits. J Urol 1990;143:671-8. (Category:Ilb) 